\title{
Mosaic Pattern of H3 K27M-Mutant Protein Expression in a Diffuse Midline Glioma-A Diagnostic Dilemma for the Pathologist
}

\author{
Deepti Narasimhaiah ${ }^{1}$ Bejoy Thomas ${ }^{2}$ Mathew Abraham ${ }^{3}$ Rajalakshmi Poyuran ${ }^{1}$ \\ ${ }^{1}$ Department of Pathology, Sree Chitra Tirunal Institute for Medical \\ Sciences and Technology, Trivandrum, Kerala, India \\ ${ }^{2}$ Department of Imaging Sciences and Interventional Radiology, \\ Sree Chitra Tirunal Institute for Medical Sciences and Technology, \\ Trivandrum, Kerala, India \\ ${ }^{3}$ Department of Neurosurgery, Sree Chitra Tirunal Institute for \\ Medical Sciences and Technology, Trivandrum, Kerala, India \\ Address for correspondence Rajalakshmi Poyuran, MD, \\ Department of Pathology, Sree Chitra Tirunal Institute for Medical \\ Sciences and Technology, Trivandrum, Kerala 695011, India \\ (e-mail: rajalakshmi.p.19@gmail.com).
}

\begin{abstract}
Keywords

- glioma

$-\mathrm{H} 3 \mathrm{~K} 27 \mathrm{M}$

- midline

- mosaic

Diffuse midline glioma, H3 K27M-mutant, is a World Health Organization (WHO) grade IV glioma arising in pons, thalamus, and spinal cord. They show mutations resulting in replacement of lysine at position 27 by methionine (K27M) of histone genes, H3F3A, HIST1H3B, and HIST1H3C. The H3 K27M mutant protein is identified in tumor tissue by immunohistochemistry. As these mutations are clonal and homogeneous, the mutant protein is normally identified in all tumor cells. Here we report a case of diffuse midline glioma with mosaic pattern of expression of $\mathrm{H} 3 \mathrm{~K} 27 \mathrm{M}$ mutant protein and discuss the diagnostic and therapeutic implications of this unusual pattern.
\end{abstract}

\section{Introduction}

Diffuse midline glioma, H3 K27M-mutant, is a novel entity described in the 2016 World Health Organization (WHO) classification of tumors of the central nervous system that correspond to WHO grade IV. In this report, we present a rare case of diffuse midline glioma with a mosaic pattern of expression of H3 K27M-mutant protein.

\section{Case History}

A 34-year-old lady presented with left-sided progressive weakness for the last 2 months; magnetic resonance imaging of brain revealed a $2.7 \times 1.9 \times 2.6 \mathrm{~cm}$ solid and cystic tumor involving the right thalamus and upper brainstem with a

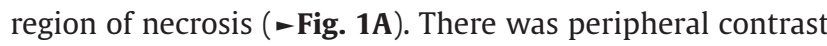

enhancement ( - Fig. 1B) with associated diffusion restriction and blooming. The patient underwent gross total resection of the tumor.

Histopathological examination revealed a high-grade astrocytoma ( - Fig. 1C, D). The tumor cells were positive for OLIG2 ( - Fig. 1E) and negative for R132H-mutant IDH1 ( $\boldsymbol{- F i g . ~ 1 F ) . ~ T h e r e ~ w a s ~ l o s s ~ o f ~ n u c l e a r ~ e x p r e s s i o n ~ f o r ~ A T R X ~}$ ( - Fig. 1G) and few nuclei expressed p53. The MIB-1 labeling index was $15 \%$ ( - Fig. 1H). K27M-mutant H3 was expressed by small clusters and single tumor cells ( - Fig. 1I, J), and endothelial cells were negative. Based on these morphological features, a diagnosis of glioblastoma, not otherwise specified, WHO grade IV, with a comment regarding the staining pattern of $\mathrm{H} 3 \mathrm{~K} 27 \mathrm{M}$ mutant protein, was rendered. Sequencing for IDH1/2, H3F3A, HIST1H3B, and HIST1H3C genes could not be performed. published online May 10, 2021
DOI https://doi.org/

10.1055/s-0041-1728231

ISSN 0976-3147
(C) 2021. Association for Helping Neurosurgical Sick People.

This is an open access article published by Thieme under the terms of the Creative Commons Attribution-NonDerivative-NonCommercial-License, permitting copying and reproduction so long as the original work is given appropriate credit. Contents may not be used for commercial purposes, or adapted, remixed, transformed or built upon. (https://creativecommons.org/licenses/by-nc-nd/4.0/).

Thieme Medical and Scientific Publishers Pvt. Ltd. A-12, 2nd Floor, Sector 2, Noida-201301 UP, India 

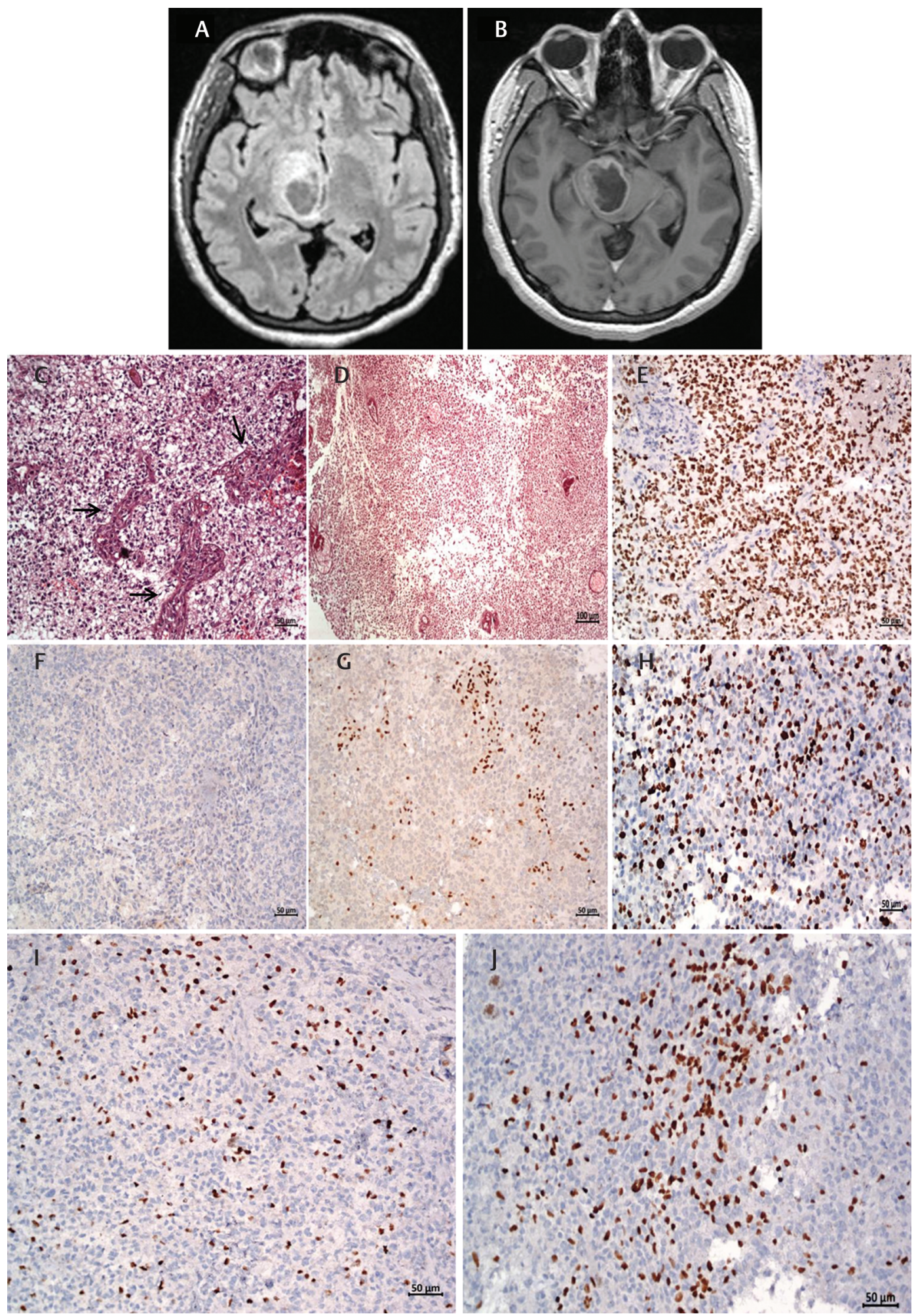

Fig. 1 Imaging and histopathological features. Axial fluid-attenuated inversion recovery image (A) shows a mass lesion with region of necrosis involving the right thalamus and upper brain stem and T1 axial postcontrast image (B) with peripheral enhancement with variable thickness of the rim and central necrosis. Microscopy reveals a high-grade glioma with microvascular proliferation (C) and necrosis (D), positive for OLIG2 (E), negative for R132H-mutant IDH1 (F), loss of nuclear expression of ATRX (G), elevated MIB-1 labeling index (H), and patchy staining for K27M-mutant H3 (I, J).

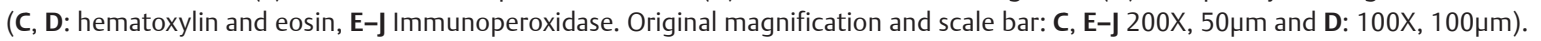

\section{Discussion}

Diffuse midline gliomas from pons, thalamus, and spinal cord show mutations resulting in replacement of lysine at position
27 by methionine (K27M) of histone genes, H3F3A, HIST1H3B, and HIST1H3C. ${ }^{1-3}$ Within the brain, these mutations occur exclusively in midline gliomas. The histone mutations are associated with mutations in genes involved in cell cycle 
regulation (TP53, PPM1D), chromatin remodeling (ATRX), and growth factors (ACVR1). ${ }^{4}$ These oncohistone mutations are considered to be initial genetic events in diffuse midline gliomas. They are clonal and homogeneous with high allelic frequency resulting in their presence in all tumor cells. ${ }^{4,5}$

In routine histopathology practice, the histone mutations in diffuse midline gliomas are identified by immunohistochemistry using antibodies against $\mathrm{H} 3 \mathrm{~K} 27 \mathrm{M}$ mutant protein. The mutational homogeneity is reflected in the uniform staining of majority of tumor cell nuclei by H3 K27M mutant protein. ${ }^{6,7}$

The mosaic pattern of staining for K27M-mutant $\mathrm{H} 3$ antibody in diffuse midline gliomas is an uncommon occurrence. The two cases reported by Lopez, et al, were diffuse midline gliomas histologically corresponding to WHO grade IV and III, respectively, harboring H3F3A K27M mutations at subclonal allele frequency. This was reflected in immunostaining of only some tumor cells for H3 K27M mutant protein. ${ }^{8}$

The mosaic pattern of staining for $\mathrm{H} 3 \mathrm{~K} 27 \mathrm{M}$ mutant protein in diffuse midline gliomas raises questions regarding grading and classification for pathologists. First, what WHO grade should be assigned for a diffuse midline glioma demonstrating patchy staining for $\mathrm{H} 3 \mathrm{~K} 27 \mathrm{M}$ mutant protein and low-grade histologic features? Second, should these tumors be classified as "Diffuse midline glioma, H3 K27M-mutant"?

One clinical trial (https://clinicaltrials.gov/ct2/show/ NCT02960230) is assessing the utility of synthetic peptide vaccine specific for the H3.3.K27M epitope with nivolumab in diffuse midline gliomas. In view of these novel strategies, the mosaic, subclonal pattern of H3 K27M mutation could have therapeutic implications.

In conclusion, we report a rare diffuse midline glioma with mosaic pattern of H3 K27M mutant protein expression and discuss the diagnostic and therapeutic implications.

\section{Funding}

None.

\section{Conflict of Interest}

None declared.

\section{References}

1 Louis DN, Perry A, Wiestler OD, et al (Eds). WHO Classification of Tumours of the Central Nervous System (Revised 4th edition). Lyon, France: World Health Organization; 2016

2 Schwartzentruber J, Korshunov A, Liu XY, et al. Driver mutations in histone $\mathrm{H} 3.3$ and chromatin remodelling genes in paediatric glioblastoma. Nature 2012;482(7384):226-231

3 Gessi M, Gielen GH, Dreschmann V, Waha A, Pietsch T. High frequency of H3F3A (K27M) mutations characterizes pediatric and adult high-grade gliomas of the spinal cord. Acta Neuropathol 2015;130(3):435-437

4 Hoffman LM, DeWire M, Ryall S, et al. Spatial genomic heterogeneity in diffuse intrinsic pontine and midline high-grade glioma: implications for diagnostic biopsy and targeted therapeutics. Acta Neuropathol Commun 2016;4:1

5 Nikbakht H, Panditharatna E, Mikael LG, et al. Spatial and temporal homogeneity of driver mutations in diffuse intrinsic pontine glioma. Nat Commun 2016;7:11185

6 Solomon DA, Wood MD, Tihan T, et al. Diffuse midline gliomas with histone H3-K27M mutation: a series of 47 cases assessing the spectrum of morphologic variation and associated genetic alterations. Brain Pathol 2016;26(5):569-580

7 Bechet D, Gielen GG, Korshunov A, et al. Specific detection of methionine 27 mutation in histone 3 variants $(\mathrm{H} 3 \mathrm{~K} 27 \mathrm{M})$ in fixed tissue from high-grade astrocytomas. Acta Neuropathol 2014;128(5):733-741

8 Lopez GY, Oberheim Bush NA, Phillips JJ, et al. Diffuse midline gliomas with subclonal H3F3A K27M mutation and mosaic H3.3 K27M mutant protein expression. Acta Neuropathol 2017;134(6):961-963 